\title{
Elastomeric Composites Surface Structure Study by Scanning Electron and Atomic Force Microscopy
}

\author{
Yu. V. Kornev ${ }^{1, a}$, H.H. Valiev ${ }^{1, b^{*}}$, A.N. Vlasov ${ }^{1, c}$, Yu. N. Karnet ${ }^{1, d}$ and \\ N.A. Semenov ${ }^{1, e}$ \\ ${ }^{1}$ Institute applied mechanics of the Russian Academy Sciences, Leningradskiy prospect 7 , \\ Moscow, Russia \\ ayurikornev@mail.ru, bhhvlv@mail.ru, ciam@iam.ras.ru, diam@iam.ras.ru, \\ esemenov.n@iam-ras.ru
}

\begin{abstract}
Keywords: Elastomeric Composites, Rice Husk Fillers, Scanning Electron and Atomic Force Microscopy, Surface Structure, Elastic Strength Properties
\end{abstract}

\begin{abstract}
New elastomeric composites were synthesized with filler particles from rice husk products both in micro and sub-micron sizes. The obtained composites surface structure was investigated by scanning electron and atomic force microscopy. The application as a prospective strengthening sub-micron sizes filler for the composite complexes creation with high elastic and strength properties have been shown.

\section{Introduction}

When creating elastomeric composites, structures and products made from such materials, considerable attention is paid to environmental issues, as well as to improving economic efficiency and energy efficiency in its production. The current interest in elastomeric composites is the problem to find effective fillers [1-6]. In this work we have investigated the surface structure of elastomeric composites based on industrial synthetic butadiene styrene rubber SBR 1500 with filler particles from rice husk products [7-8], both in micro and sub-micron sizes. These experiments are important to understand the structure-property relationships for polymer composites and are taken into account in the mathematical models creation for predicting these materials mechanical properties [9-10].
\end{abstract}

\section{Materials and methods}

Two type composites were prepared: samples 1 with micro dispersed fillers and samples 2 with sub-microdispersed fillers. High-dispersed filler particles were obtained from the micro dispersed feed using a PM100 planetary ball mill (Retsch, Germany). The composites main components were: rubber SBR $1500-100 \mathrm{wt} \%$, fillers- $65 \mathrm{wt} \%$ (filling 30\% by volume). The obtained composites surface structure was investigated by JSM-6700F-field emission scanning electron microscope with JED-2300F energy dispersion microanalyzer (Jeol, Japan). The tests were carried out in high vacuum conditions. Platinum sputtering $50 \mathrm{~nm}$ thickness was preliminarily applied on the samples surface. The sample surfaces were examined using an atomic force microscope (AFM) easyScan (Nanosurf, Switzerland) operating in half-contact mode in air at room temperature. The phase-contrast mode was additionally used in the AFM. The AFM was protected from external excitations using a TS-150 dynamic anti-vibration stage (Fabrik am Weiher, Switzerland).The vulcanizes elastic-strength properties were tested on a UTS-10 (Zwick Roell, Germany) tensile machine. 


\section{Results and discussions}

The elastomeric composites surface structure SEM image for samples with micro- or submicrodispersed fillers is shown in Fig. 1 a, b. The filler particles (light areas) in the elastomeric matrix (dark areas) are visualized in these images. The determined sizes filler agglomerates in the rubber matrix with SPIP program (Image Metrology, Denmark) for samples 1 are in the range from $200 \mathrm{~nm}$ to $10 \mathrm{mkm}$, distances between fillers about $500 \mathrm{~nm}$; for samples 2 - sizes from 30 $\mathrm{nm}$ to $1 \mathrm{mkm}$, distances - about $100 \mathrm{~nm}$. The surface structure AFM images of these industrial synthetic butadiene styrene rubber SBR 1500 composites with a micro- and nanostructured amorphous silicon dioxide filler are shown in Fig. 2 a, b (left - topography, right - phase contrast). In these images also the filler particles are visualized as a light area in the elastomeric matrix dark areas. The AFM image data analysis with respect to the filler sizes are in agreement with the SEM data.

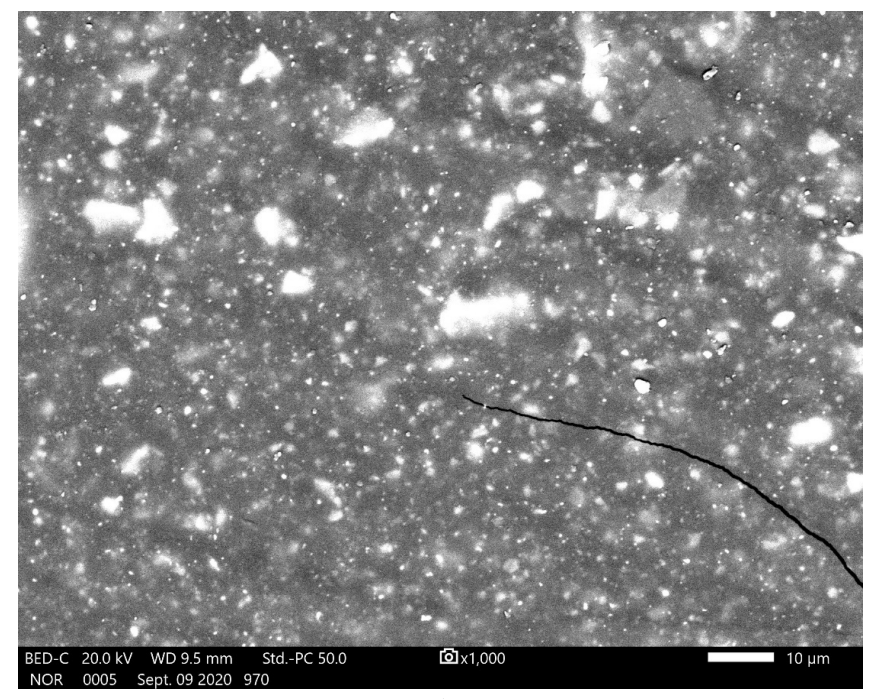

a)

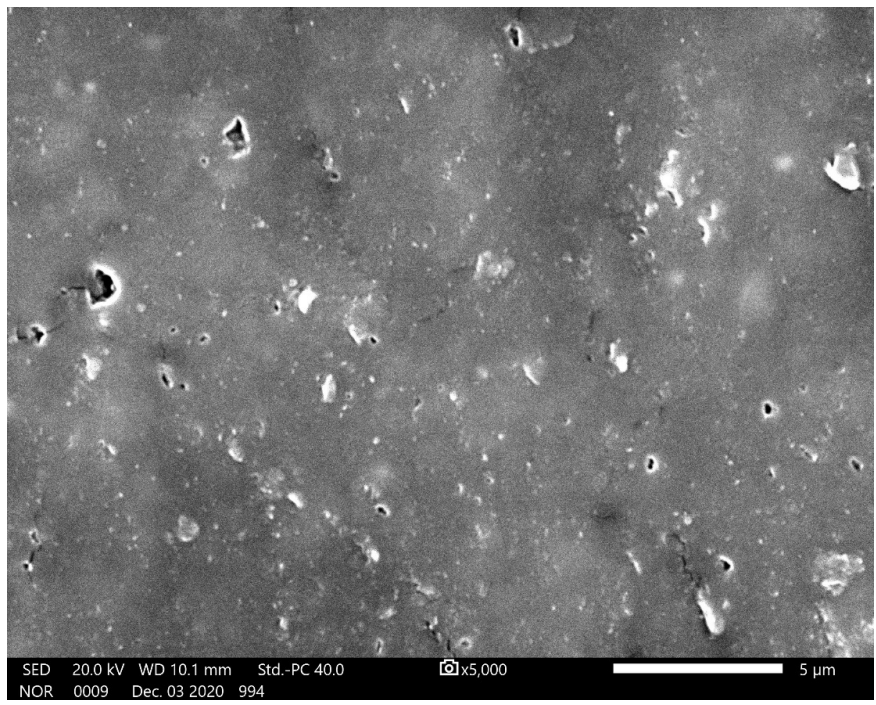

b)

Fig. 1. SEM images of elastomeric composites with different fillers: a) microdispersed amorphous silicon dioxide, b) sub-microdispersed amorphous silicon dioxide. 


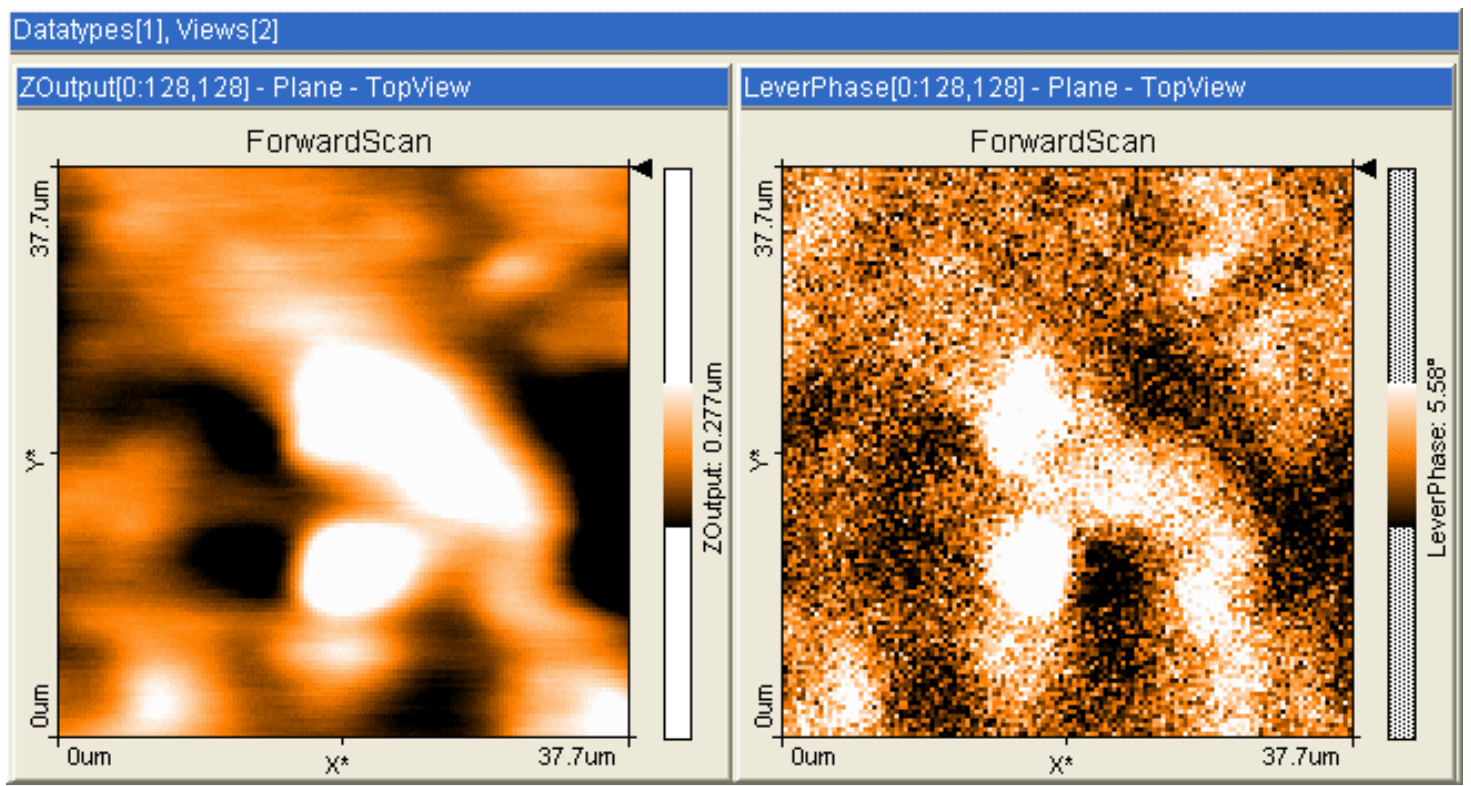

a)



b)

Fig. 2. AFM images of the surface structure on industrial synthetic butadiene styrene rubber SBR 1500 filled with:

a) microdispersed amorphous silicon dioxide. Scans $37.7 \times 37.7 \mu \mathrm{m}$;

b) sub-microdispersed amorphous silicon dioxide. Scans are $28.3 \times 28.3 \mu \mathrm{m}$.

(In each image on the left is topography, on the right-phase contrast).

The data analysis images presented in Figs. 1-2 show that when the filler particles size decreases, there is a noticeable decrease in the inclusions size (particle agglomerates), which indicates a noticeably better filler particles distribution in the elastomeric matrix. For example, sample 2 filled with sub-micron particles shows a decrease in the agglomerate average size to about $30 \mathrm{~nm}$ from the initial $200 \mathrm{~nm}$ obtained for sample 1 filled with micro filler particles. As 
follow from our strain - stress measurements on these composites performed on UTS-10 tensile machine this leads to a significant improvement in the elastic strength properties in sample 2 compared to sample 1 . Thus, sample 2 shows a 5 -fold increase in strength compared to sample 1 , and 1.5 -fold increase in tension at $300 \%$ elongation.

\section{Conclusion}

The synthesized elastomeric composites study by scanning electron and atomic force electron microscopy shows a noticeable influence the surface structure parameters of the fillers from rice husk on the complex mechanical properties. The data obtained on the used fillers distribution features in the elastomeric matrices correlate with the measured physical and mechanical properties of the synthesized composites. The efficiency of directional control over the initial particles size in amorphous silicon dioxide derived from renewable raw materials (rice husks) and their use as promising strengthening filler for creating composites with reinforced mechanical properties have been shown.

\section{Acknowledgements}

This work has been carried out on the basis of the State Assignment for the period of 2019-2021 in the IPRIM RAS. State Registration Number: AAA-A19-119012290177-0.

\section{References}

[1] Matthews F.L., Rawlings R.D. Composite Materials: Engineering and Science. N. Y., Woodhead Publishing, 1999.-470 p.

[2] Kornev A.E., Bukanov A.M., Sheverdyayev O.N. Technology of elastomeric materials. Moscow: NPPA "Istek", 2009.-504 p.

[3] Farzana Hussain, Mehdi Hojjati, Masami Okamoto, Russell E. Gorga Review article: Polymer matrix Nanocomposites, Processing, Manufacturing, and Application // Journal of Composite Materials. 2006. V. 40. P. 1511. https://doi.org/10.1177/0021998306067321

[4] Yanovsky Yu.G., Grigoryev F.V., Nikitina E.A., Vlasov A.N., Karnet Yu.N. Nanomechanical properties of polymer composite nanoclusters // Physical Mesomechanics. 2008. V. 11. № 5-6. P. 247-259. https://doi.org/10.1016/j.physme.2008.11.005

[5] Yanovsky Yu.G. Nanomechanics and strength of composite materials, Moscow: IPRIM RAS, 2008, $-179 \mathrm{p}$.

[6] Vlasov A.N., Volkov-Bogorodsky D.B., Yanovsky Y.G., Kornev Y.V., Karnet Y.N. Mechanical properties estimation in hyperelastic composites with small disperse fillers additives

// Mechanics and nanomechanics of structurally complex heterogeneous media. Successes, problems and prospects. 2015. P.219-226.

[7] Bakar R.A., Yahya R., Gan S.N. Production of high purity amorphous silica from rice husk //Procedia Chem.-2016.-V.19.-P.189-195. https://doi.org/10.1016/j.proche.2016.03.092

[8] Liu X., Chen X., Yang L.,Chen H., Tian Y., Wangn Z. A review on recent advances in the comprehensive application of rice husk ash //Res. Chem. Intermed.-2016.-V.42.-P.893-913. https://doi.org/10.1007/s11164-015-2061-y

[9] Kornev Y.V., Semenov P.E., Semenov N.A., Solyaev Y.O., Kh. Valiev Kh. Mechanical properties of elastomeric composites reinforced by particles of mineral fillers based on silicon oxide and carbon // Collection: XII All-Russian Congress on Fundamental Problems of Theoretical and Applied Mechanics - Proceedings. In 4 volumes. 2019. P. 1433-1435.

[10] Valiev H.H., Vlasov A.N., Kornev Yu.V. et al. Scanning probe microscopy of elastomers with mineral fillers //Composites from Renewable and Sustainable Materials.-London: Intechopen, 2019.-P. 39-50. 